\title{
JUN 141960
}

CDNF-650510-6

Guided Flying Spot Systems for Spark Chambers *

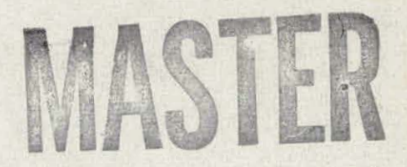

Martin Deutsch

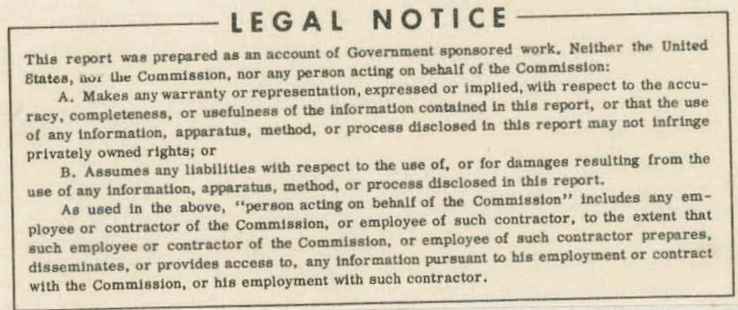

LEGAL NOTICE

report was proped as a a

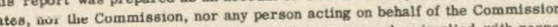

tion contained in this report, or that the use

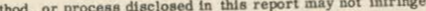

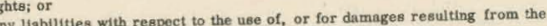
B. Assumes any lo pparatus, method, or process disciosed in thils report.

with the Commission, or his employment with such contractor.

\section{PATENT CLEARANCE OBTAINED. RELEASE TO \\ THE PUBLIC IS APPROVED. PROCEDURES \\ - ARE ON EILE IN THE RESEIVING SECTION,}

Invited talk given at the Purdue Conference on Instrumentation for High Energy Physics, May12-14,1965.

* This work is supported in part through A.I.C. Contract Ar (30-1)-2098. 


\section{DISCLAIMER}

This report was prepared as an account of work sponsored by an agency of the United States Government. Neither the United States Government nor any agency Thereof, nor any of their employees, makes any warranty, express or implied, or assumes any legal liability or responsibility for the accuracy, completeness, or usefulness of any information, apparatus, product, or process disclosed, or represents that its use would not infringe privately owned rights. Reference herein to any specific commercial product, process, or service by trade name, trademark, manufacturer, or otherwise does not necessarily constitute or imply its endorsement, recommendation, or favoring by the United States Government or any agency thereof. The views and opinions of authors expressed herein do not necessarily state or reflect those of the United States Government or any agency thereof. 


\section{DISCLAIMER}

Portions of this document may be illegible in electronic image products. Images are produced from the best available original document. 
As experience with fully automatic scanning and measuring of spark chamber photographs is bcginning to accumulate, it becomes clear that the distinction between raster-scan and programmed-scan systems is less significant than we had believed.

The problems of both methods are primarily in the area of programing. The crucial operation of linking basic information elements - i.e. spark coordinates - into tracks and trajectories is very similar whether the original film or its image in core storage is used as random-access memory.

The two extreme examples of the two systems are the HPD mechanical scanner, or its CRT analogue luciole as a pure raster scan, and the SPASS system as a tightly programed scan. Yet the program siructures are very similar on the logical level and in the "housekeeping" aspects, such as the classification and disposition of failures.

Even the classification of a perticular system as belonging to one or the other of the two types is not clear-cut, except for the extreme cases. Luciole, at $\mathrm{CERN}$, uses no computer-stored information to gulde its operation. It can therefore be used off-line without significantly changing its operation, storing the output on magnetic tace for later processing.

CHLOE, at Argonne National Laboratory, uses computer-stored information to determine the areas to be scanned, e.g. the locations of spark chamber gaps and data lights. But the only modification of this information derived from the film itself is the adjustment of the coordinate system with respect to the fiducial marks. Apart from this, the data are gathered by a restricted raster scan. This system with its very sophisticated programs has now begun to produce physics and will be described in another paper at this meeting.

ARIANE, at Orsay, uses a very tight feedback between fiducial Ines on the film and the scan lines searching the gaps. However in this system, as in Luciole and CHLOE, all "hits" are stored in the output and connected subsequently. ARIANE has already produced physics and will be described in a subsequent paper.

There are now several systems operating, derived from the original SPASS system. Prof.Brenner at Harvard University has'a system which involves some significant improvements in hardware and in programs and which has begim to produce results. SASS, at the University of California, Berkeley, employs ackT of much higher resolution and a 
somewhat more powerful computer. It has, however, not yet been usied in an experiment.

SPASS is programmed to utilize all available information, either stored initially or gathered from the film, to guide the scan.

This maximal feedback was originally imposed on the system by the relatively slow operation of the available display which put a high premium on restricting the number of imege points interrogated. Most of the steps in geometric reconstruction are also carried out as soon as the information is available. The output consists, typically, of track coordinates and angles, including stereo correlation, but never of spark coordinates. This system has now operated for three years and has successfully processed five distinct experiments. Most of the remainder of my report is based on experience with the SPASS system.

The principal practical differences in the use of the two types of systems arise from the fact that the amount of' information which must be stored and processed at any stage is much smaller for the programmed scan. This permits operation with a small computer which can be kept available and under the control of the experimenter. Perhaps this advantage will diminish with time. More powerful computers move into the "small" class and time-shared operation of large installations, using a very small computer as interface begins to be feasible. It is usually easier to find programming competence for a large computeriwhere most of the program can be written in FORTRAN, than for the small computer which may not permit the use of a compiler in this application. These questions involve the sftusition in each particular laboratory and cannot be resolved by general principles.

The differences between the two systems diminish also as the pictures become more complex and their information content increases. The program scan shows its greatest strength with "hodescope" chambers which contain only one or two tracks for a valid event since the area to be searched can be very rapidily restricted after the first track segments have been located. On the other hand, if a large chamber has to be searched for tracks which may originate anywhere in its volume and connect in a variety of configurations, all of the gaps must be searched completely by either system. There. does, however, remain the basic difference between a system which - itentifies immediately at least the basic information elements, such as sparks, and one which simply records "hits" which must later be 
combined into information elements.

In the programmed scan system the "understanding" of the picture develops in the computer as the scan progresses and this permits the operator to follow the operation, on a slave oscilloscope and to spot very quickly the difficulties encountered. This.feature, which we foumd of decisive importance in the initial stages of our experience is now less crucial since most of the difficulties encountered are only varlations of familiar ones, previously resolved by us or by others.

In the future, the programmed spot may have advantages if more varied types of pictures have to be analyzed. For example if we have to search for objects of a particular shape and density among many others the number of "hits" of diffrenet types may be too large for convenient accessible storage and the required real-time filtering may be more èasily accomplished by tight feadback.

Figure I shows a typical "hodoscope" photograph of four spark chambers defining the particle trajectories through a magnet. The views are arranged on the film in such a manner that each event can be scanned in two successive single-fraine advances, covering the picture taken in a single double-freme exposure. This method of increasing the resolution is convenient for the low-resolution CRT used in SPASS at present. Scanning strategy calls for the measurement of fiducials in each view. Marks directed perpendicular to the relevant coordinate axis have been found most convenient and precise. The scan direction for each object is programed to follow the local coordinate axis. Tolerances are set for locations of fiạucials and for numbers missed.

Whenever a failure occurs, the scanning is interrupted and the computer types out the frame number and the error, e.g. the fiducial missed or displaced, excessive number of tracks, etc. The operator can usually determine in a few seconds whether a special situation exists on the rejected frame. We have found that this procedure avoids a great deal of rescanning which becomes necessary if the computer simply continues after rejecting an event. Some films may have scratches along their entire length. Some fiducial lights may fail for certain periods. Such problems can be immediately resolved by on-line program modification. No halt occurs, of course, for 
-- "physics" rejections, such as empty chambers.

Figure 2 shows a photograph from the BNL-Maryland $K_{0}$ mass determina-

... tion experiment. Figure 3 shows a photograph of the actual spass scan of such an event.

In this case the program searches for $V$ events by following tracks forward through three chambers towards the vertex. The first chamber is searched to a predeterminea depth for track origins. The track segment in each view is constructed in local scan coordinates and continued into the next chamber after transformation to real-space coordinates. A certain amount of ingenuity was required to deal with events which appear under a small angle in one viev. It was found that the use of multiple matching criteria for track segments resulted in remarkable stability of the decision even when the prograsa contained some logical errors.

our greatest prograrming worxies concern electromagnetic showers. In the past we have been able to avoid many of the problems because our events never involved more then one shower and only the vertex position had to be determined. We are now attempting to deal with more difficult situations and I should be grateful for any contributions which may be made during the discussion.

$I$ should now like to report a few points of exprience gained in actual operation. The first point concerns the time required in preparation for' a new experiment. In general, about two months of intensive work can produce a program which will scan film with sufficient efficiency to permit evaluation while the experiment is in progress, provided the development of the program and the apparatus are carried out in close coordination. This first version may still have a rejection rate of 25 percent of valid events. This can be reduced very rapidly to about 15 percent simply by eliminating obvious mistakes. A more intensive investigation of specific difficulties may reduce this to about 10 percent. Beyond this point progress tends to be slow because we now deal with many minor difficulties, each of which occurs oniy very rarely and cannot be resolved until it has heen encountered at least once. This stage of the developments is greatly reduced in importance as experience accumulates and provision for these difficulties can be made in the original program. At some level near 5 percent we encounter a hard core of rejections which are due to nearly unique situations and cannot be eliminated withouf excessive effort.

We have found it adrantageous to determine yields by examining 
only pictures for which marginal rejection is indicalea, e.g. a single missing segment or failure of stereo identification, rather than by: statistical comparison with hand scanned data.

This whole process of program improvement should take about onemonth of intensive work. In practice, the elapsed time has been more nearly six months, probably because the effort occurs at a tine when other aspects of the experiment also need our attention in the light of the initial scanning results. As experience accumulates, the effort required for each new experiment diminishes and we can now take a large and increasing fraction of each program from an existing library.

The importance of planning the entire experiment, including the acceleratior exposure and the subsequent data processing as a complete system cannot be overemphasized. An experiment cannot be considered ready for execution until the evaluation program is in as good a state of functioning as the on-line electronics. 